\title{
"As moedas dos índios": um estudo de caso sobre os significados do patrimônio arqueológico para os moradores da Vila de Joanes, ilha de Marajó, Brasil
}

"The coins of Indians": a case study about the meanings of Archaeological heritage to the local communities of Vila de Joanes, Marajó Island, Brazil

\author{
Marcia Bezerra \\ Universidade Federal do Pará. Belém, Pará, Brasil
}

\begin{abstract}
Resumo: $\bigcirc$ artigo apresenta os resultados iniciais do projeto de Arqueologia Pública conduzido pela autora em Joanes uma pequena vila de pescadores na ilha de Marajó, estado do Pará, Brasil -, considerando as ruínas de um sítio histórico (PA-JO-46) associado a uma missão religiosa instalada na vila por volta da segunda metade do século XVII. As reflexões sobre as percepções das comunidades locais acerca do sítio sublinham o entendimento da lógica subjacente ao ato de colecionar artefatos - prática local comum - e à formação de pequenas 'coleções domésticas'. Meu argumento é de que o colecionamento, nesses contextos, não pode ser classificado como ato de destruição, mas como uma forma singular de fruição do passado e do patrimônio. Acredito que essa discussão contribua para a compreensão das relações entre comunidades de pequena escala e o patrimônio arqueológico na Amazônia.
\end{abstract}

Palavras-chave: Arqueologia pública. Cultura material. Coleção. Arqueologia amazônica. Ilha de Marajó.

\begin{abstract}
The paper address the preliminary results of the Public Archaeology project that is being conducted by the author at Joanes, a small fishermen village in Marajo Island, state of Pará, Brazil, considering the ruins of an historic site assigned to a religious mission from the late XVIIth Century. The reflections about the local communities' perceptions of the site highlight the underlying logic of collecting artifacts - a local common practice - and the subsequent organization of small 'domestic collections'. I argue that collecting in these contexts should not be regarded as looting or destruction, but as a singular form of heritage and past appropriation. I believe this discussion will contribute to the understanding of the relationship between small scale communities and the archaeological heritage in Brazilian Amazon.
\end{abstract}

Keywords: Public Archaeology. Material culture. Collection. Amazonian Archaeology. Marajó Island.

Como citar este artigo: BEZERRA, Marcia. "As moedas dos índios": um estudo de caso sobre os significados do patrimônio arqueológico para os moradores da Vila de Joanes, ilha de Marajó, Brasil. Boletim do Museu Paraense Emílio Goeldi. Ciências Humanas, v. 6, n. 1, p. 57-70, jan.-abr. 2011.

Autor para correspondência: Marcia Bezerra. Universidade Federal do Pará. Instituto de Filosofia e Ciências Humanas. Programa de Pós-Graduação em Antropologia. Rua Augusto Corrêa, 01 - Guamá. Belém, PA, Brasil. CEP 66075-110 (mar.bezerra@uol.com.br).

Recebido em 08/06/2010

Aprovado em 10/03/2011

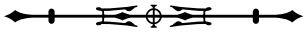




\section{INTRODUÇÃO}

O presente artigo trata das relações entre os moradores da Vila de Joanes, um distrito do município de Salvaterra, situado na ilha de Marajó (PA), e o patrimônio arqueológico local. As discussões apresentadas são resultantes da primeira etapa de pesquisa de projeto coordenado pela autora e orientado pelas perspectivas da Arqueologia Pública e da Arqueologia Etnográfica, cujo objetivo principal é a compreensão das representações dos moradores acerca das ruínas do Sítio Histórico de Joanes (PA-JO-46) e das práticas sociais locais a respeito dos materiais arqueológicos dispersos por toda a vila.

Entre essas práticas, destacamos o ato de colecionar objetos arqueológicos encontrados de maneira fortuita na praia, nas ruas e nas pequenas roças domésticas. Os moradores formam pequenas coleções de louças, cerâmicas e moedas coletadas, sobretudo, pelas crianças. A formação dessas 'coleções domésticas' é recorrente na Amazônia, em especial nas vilas assentadas sobre antigas aldeias. Contudo, não há pesquisas sobre o tema, que tem desdobramentos importantes para as reflexões acerca das relações entre 'pessoas e coisas' (Bell e Geismar, 2009) e para a gestão do patrimônio arqueológico na região.

Nesse sentido, apresento algumas reflexões que implicam a crítica e a desconstrução da oposição básica entre colecionismo e preservação do patrimônio. Ressalto que me refiro apenas ao tipo de colecionismo tal como praticado por comunidades de pequena escala, como a da Vila de Joanes.

\section{O PASSADO AMEAÇADO DA AMAZÔNIA}

Pesquisadores e gestores buscam há décadas por soluções para conter a destruição do patrimônio arqueológico na Amazônia. A política de fiscalização empreendida por órgãos de gestão, em nível federal e estadual, somada aos projetos de Educação Patrimonial - cujo desenvolvimento no âmbito da Arqueologia de Contrato é uma exigência no Brasil - são considerados fundamentais na luta pela preservação (Bezerra, 2010).

A legislação brasileira protege o patrimônio arqueológico, quer ele esteja em propriedade pública ou privada, e os agentes da destruição são punidos por meio de processos judiciais, que implicam desde a aplicação de multas até a decretação de prisão (conforme Decreto Lei 3.924/1961, disponível em Coletânea..., 2006).

Os esforços têm se mostrado insuficientes no combate ao saque, ao vandalismo e ao tráfico de peças arqueológicas: uma realidade crescente na Amazônia. Os fatores que mais contribuem para a degradação do patrimônio são: 1) o tráfico de peças arqueológicas; 2) a retirada de terra preta para comercialização; 3) a implantação de projetos de desenvolvimento; e 4) o turismo desordenado (Schaan, 2007; Lima, 2007).

Na ilha de Marajó, fazendeiros locais e intermediários de colecionadores do Brasil e do exterior encomendam vultosos saques aos sítios associados à Fase Marajoara, aumentando a categoria de "subsistence diggers" (Brodie, 2006, p. 5). Meu interesse, neste artigo, não é com essa categoria, mas com os formadores de pequenas coleções domésticas.

Nas comunidades de pequena escala', na Amazônia, as casas se assentam sobre os sítios arqueológicos, os moradores fazem suas roças nos sítios de terra preta, armazenam água e farinha em urnas funerárias, guardam objetos encontrados na beira de rios, igarapés, nas ruas de terra e reúnem artefatos para as suas coleções. Mas será que os membros dessas comunidades pertencem à mesma categoria dos grandes colecionadores? Será que, de fato, representam uma ameaça ao patrimônio arqueológico?

Sob a ótica da legislação brasileira, todos praticam atos ilegais, que contrariam as perspectivas patrimoniais de preservação. Em minha perspectiva, aqueles sujeitos participam desse 'jogo' do patrimônio de formas distintas,

1 Entendo uma 'comunidade de pequena escala' em função das fronteiras claramente marcadas, dos estreitos laços de parentesco entre os moradores. No caso de Joanes, acrescento a observação da categoria de "filhos de Joanes", criada em oposição aos "forasteiros" (ver Elias e Scotson, 2000).

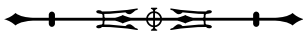


o que implica o redirecionamento de nosso olhar sobre a questão. Não apoio atos que promovam a destruição, mas concordo com Belk (2008, p. 539) no sentido de que há poucas pesquisas sobre a prática do colecionamento e que sua necessidade reside no fato de que "(...) appears to be diverse types of collectors and diverse reasons to collect". As populações amazônicas, neste caso, os moradores da Vila de Joanes, constituem um estudo emblemático dessa situação.

\section{O CONTEXTO}

Joanes é uma pequena vila de pescadores muito procurada por turistas brasileiros e estrangeiros. No mês de julho, em função do verão amazônico, a sua população chega a triplicar em tamanho. A economia é baseada na pecuária, na agricultura, no extrativismo vegetal, na pesca e no turismo. A vila está localizada na porção leste da ilha de Marajó, estado do Pará, que, por sua vez, está situada em um arquipélago no delta do rio Amazonas, na porção norte da América do Sul.

A ilha compreende distintas paisagens de campos e florestas ${ }^{2}$ pontilhadas por sítios arqueológicos, cujas datações apontam para uma longa ocupação, indo desde 5.000 A.P. até a chegada dos europeus, no século XVI. Pouco se sabe sobre os sambaquis que caracterizam as primeiras ocupações. A história pré-colonial do Marajó é conhecida, principalmente, pelas pesquisas realizadas nos tesos associados à Fase Marajoara, cujos estudos realizados, desde a década de 1950, por pesquisadores como Meggers e Evans (1954), Brochado (1980), Roosevelt (1991) e Schaan (2001), alimentam acirrados debates acerca da emergência de sociedades complexas na Amazônia pré-colonial. Parte da população remanescente da Fase Marajoara parece ter sido incorporada às missões religiosas implantadas na ilha a partir do século XVII (Marques e Bezerra, 2008; Schaan e Marques, 2006; Schaan, 2009).

A expressão numérica da população indígena que habitava o norte do Brasil transformou esse território em um dos principais atrativos para a tarefa missioneira durante o período colonial (Fausto, 2003, p. 91). Boa parte da história da colonização portuguesa na América se desenrolou longe dos grandes núcleos administrativos. Vilas e povoados formados em lugares distantes acabaram por se assemelhar a pequenas 'ilhas', nas quais emergiram novos modos de vida, resultantes do confinamento, do isolamento e do convívio estreito entre indivíduos com distintos pertencimentos (Mello e Souza, 1997).

Foi nesse contexto, no século XVII, que se estabeleceu a missão religiosa na então denominada Vila de Monforte. As evidências encontradas durante as pesquisas arqueológicas (Schaan e Marques, 2006; Marques e Bezerra, 2008, 2009) revelam o cotidiano dessa missão e a interação entre indígenas e europeus, o que torna o estudo e a preservação do sítio de Joanes fundamentais para a compreensão do processo de contato na Amazônia colonial.

\section{AS PESQUISAS ARQUEOLÓGICAS NO SÍTIO HISTÓRICO DE JOANES (PA-JO-46)}

O sítio histórico de Joanes (Figura 1) é constituído por vestígios indígenas, coloniais e ruínas da Igreja de Nossa Senhora do Rosário, integrantes da antiga missão religiosa (Schaan e Marques, 2006). Tanto os franciscanos como os jesuítas podem ter sido os responsáveis pela obra e pela fundação da igreja, que talvez represente a primeira missão religiosa a se estabelecer na ilha de Marajó (Lopes, 1999).

A importância histórica e arqueológica do sítio motivou o Instituto do Patrimônio Histórico e Artístico Nacional (IPHAN) a desenvolver projetos visando a sua preservação. Em 1986, durante a ampliação do prédio da escola local, foram encontrados vestígios da antiga missão, o que implicou a realização de uma pesquisa de salvamento. Em 1999, Lopes (1999) abriu pequenas sondagens, mapeou o material de superfície e fez levantamento em fontes históricas, resultando em sua dissertação de mestrado. Em 2006, o IPHAN, preocupado com o

\footnotetext{
2 Para uma discussão sobre os distintos 'Marajós', ver Pacheco (2006).
} 


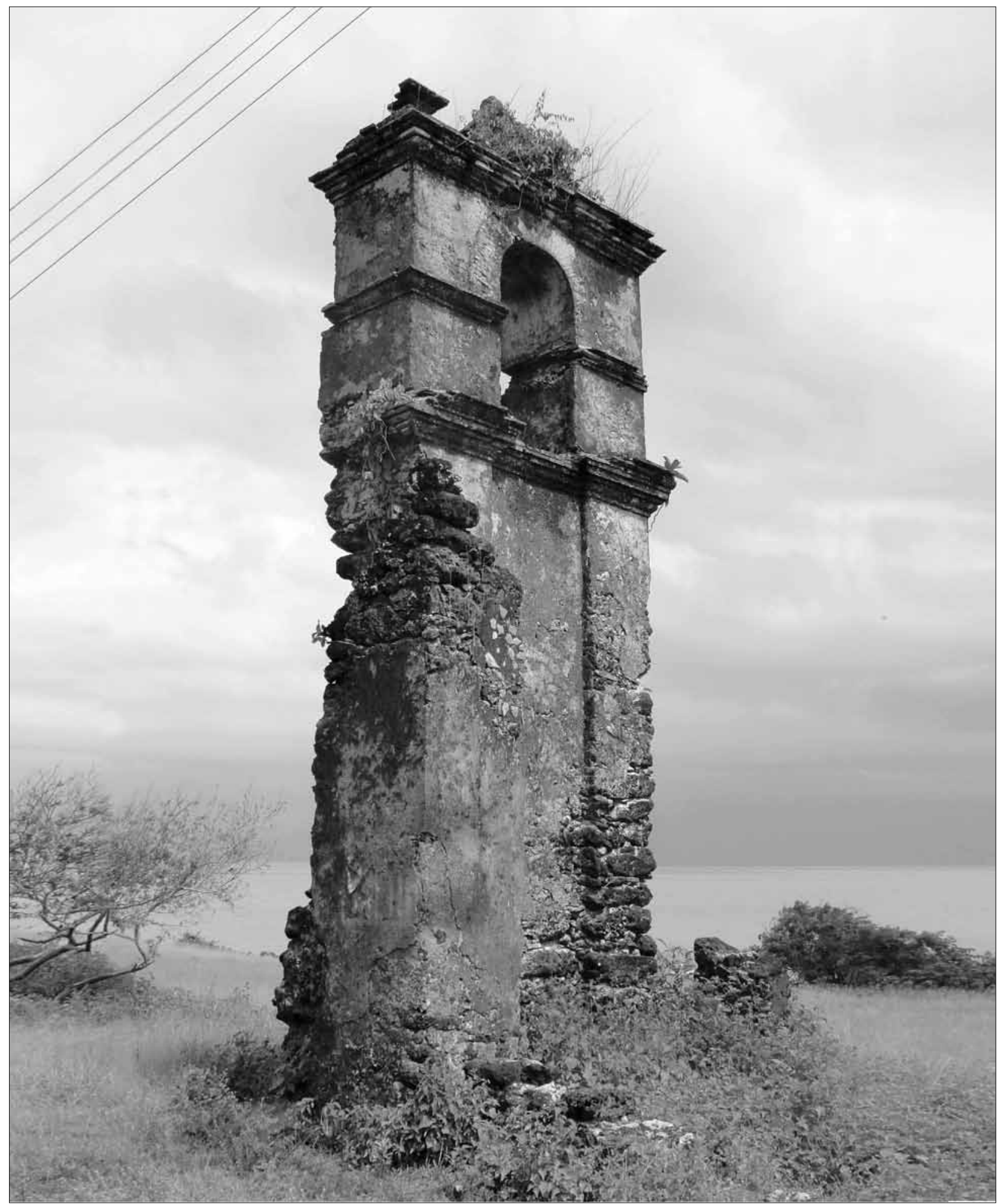

Figura 1. Sítio PA-JO- 46. Foto: Flávio L. Silveira.

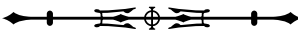


estado de preservação das ruínas, financiou um projeto de pesquisa e de educação patrimonial, que foi conduzido em parceria com a comunidade. Entretanto, disputas políticas travadas nas eleições municipais implicaram o uso do patrimônio arqueológico como instrumento de representação de um dos grupos politicamente ativos da vila. Os conflitos internos acabaram provocando a destruição das placas de sinalização turística colocadas pelos pesquisadores. As críticas dos moradores sobre a retirada do material arqueológico da vila, uma vez que não havia local adequado para a sua guarda, levaram os pesquisadores a optar por deixar parte do acervo sob a responsabilidade da escola, onde se mantém até os dias de hoje (Schaan e Marques, 2006) . $^{3}$

Com o objetivo de retomar as relações com a comunidade local e reparar os danos causados à sinalização do sítio, o IPHAN financiou um novo projeto de pesquisa arqueológica e educação patrimonial, que teve início em 2008. O projeto, coordenado pelo arqueólogo Fernando Marques, responsável por intervenções anteriores, e por mim, tinha objetivos e problemas análogos ao projeto de 2006. A chegada dos pesquisadores à vila foi marcada por um clima de desconforto e desconfiança. Ao longo do projeto, a equipe procurou se integrar à vida da comunidade local, incluindo os moradores na pesquisa de campo, realizando reuniões com pequenos grupos, participando de suas festas e observando suas atitudes com relação ao patrimônio arqueológico. Distantes do clima político enfrentado pela equipe anterior, os moradores, aos poucos, passaram a procurar pelos pesquisadores para discutir assuntos de interesse local, como a construção de um museu para 'contar a história de Joanes' e a curiosidade sobre o andamento das escavações.

Durante a última etapa de campo, foi instalada uma bancada com objetos recuperados nas escavações, ao lado de uma das quadrículas e, posteriormente, uma exposição na escola (Marques e Bezerra, 2009). Ambas as situações revelaram mudanças nas atitudes dos moradores com relação ao patrimônio arqueológico local e, ao mesmo tempo, salientaram a necessidade de entendermos a lógica subjacente ao colecionamento e à relação com as ruínas. Foi com base nessas inquietações que elaborei o projeto de Arqueologia Pública, iniciado em setembro de 2009 , e que é objeto deste artigo.

\section{O PROJETO DE ARQUEOLOGIA PÚBLICA: PRIMEIRAS REFLEXÕES}

As reflexões aqui contempladas resultam, portanto, de etapa inicial da pesquisa. A articulação da Arqueologia Pública com a Etnografia, onde a "Archaeology is a Subject of Ethnography", de acordo com Castañeda (2008, p. 30-31), é o fio condutor do projeto.

As reflexões acerca das relações entre a Arqueologia e a Etnografia ganham cada vez mais espaço na literatura arqueológica. Pesquisas conduzidas em distintos contextos têm possibilitado repensar o lugar da etnografia na pesquisa arqueológica (Edgeworth, 2006; Hamilakis e Anagnostopoulos, 2009; Mortensen e Hollowell, 2009; Castañeda e Matthews, 2008). Alguns autores, ao enfatizarem a perspectiva histórica da chamada Etnoarqueologia, mostram os distintos caminhos percorridos - de método à subdisciplina - e analisam os desafios contemporâneos. Entre eles, a necessidade de se considerar o impacto do valor histórico de objetos e estruturas na formação do registro arqueológico num dado contexto, e ainda pensar as formas pelas quais as sociedades praticavam a sua "própria arqueologia" no passado (Lane, 2008, p. 418). Outros, como Castañeda (2008), indicam o surgimento de novos sentidos na relação entre Arqueologia e Etnografia (Castañeda, 2008; Meskell, 2005).

Em seu artigo "The 'Ethnographic Turn' in Archaeology: research positioning and reflexivity in Ethnography",

3 O material seria levado para o Museu Paraense Emílio Goeldi, responsável pela salvaguarda desse acervo. A permanência de parte das coleções na escola local foi autorizada pelo IPHAN. 
Castañeda (2008, p. 30-32) trata de três modos distintos de articulação entre a Etnografia e a Arqueologia: 1) Etnografia arqueológica: a Etnografia é um método da Arqueologia empregado para o estudo do passado arqueológico; 2) Antropologia da Arqueologia: a Arqueologia é um objeto da Etnografia, sendo a Arqueologia estudada como fenômeno sociocultural contemporâneo; e 3) Arqueologia etnográfica: a Arqueologia é sujeito da Etnografia. Métodos etnográficos são incorporados ao fazer arqueológico para estudar o passado e os contextos sociais presentes.

É nesta última categoria - Arqueologia etnográfica - que se insere a nossa pesquisa, orientada pela ideia de "(...) pervasive integration of ethnographic processes into the doing of archaeology in several different registers and domains of the research Project" (Castañeda, 2008, p. 40).

Arqueologia Pública é uma vertente da Arqueologia preocupada em compreender as relações entre distintas comunidades e o patrimônio arqueológico, considerando o impacto do discurso acadêmico em sua visão de mundo, o lugar de suas narrativas na construção do passado e a gestão comunitária dos bens arqueológicos (Bezerra de Almeida, 2003; Funari, 2004; Pyburn e Wilk, 2000; Schaan, 2007). Como se vê, a Arqueologia Pública é, ao mesmo tempo, produto e vetor de reflexões acadêmicas, de ações políticas e de estratégias de gestão.

Muitos autores (Pyburn e Bezerra, 2006; Pyburn e Wilk, 2000) entendem a Arqueologia Pública como Antropologia Aplicada (Pyburn e Bezerra, 2006; Shackel e Chambers, 2004). A pesquisa aplicada, diferente da pesquisa básica, tem por objetivo solucionar problemas dos indivíduos envolvidos no projeto de pesquisa. Os resultados da pesquisa básica também podem contribuir para mudar a vida dos grupos estudados, mas essa não é a sua principal questão (LeCompte e Schensul, 1999).

AArqueologia Pública, nessa perspectiva, tem papel importante como instrumento de ação política e social. trabalho do arqueólogo é de natureza interventiva, desde o momento de sua chegada ao local, onde as pesquisas de campo terão lugar, até as interpretações dos vestígios arqueológicos e a consequente construção de uma dada visão do passado. A Arqueologia Pública lida, especialmente, com essa faceta de nosso trabalho e propõe não apenas o reconhecimento do 'outro', mas a sua participação em todo o processo investigativo, assim como o gerenciamento comunitário do patrimônio arqueológico.

Assim, entendo que a Arqueologia Pública é uma forma de praticar a Arqueologia e que compreende o fazer arqueológico dentro de uma perspectiva circular (Bezerra, 2009b), na qual as narrativas locais sobre o passado são consideradas na construção e na reorientação das pesquisas acadêmicas; e não como um conjunto de ações para o público, entendido de maneira genérica.

A partir dessas duas abordagens, pretendo contribuir para a avaliação crítica do ethos da Arqueologia em relação às comunidades locais na região amazônica e para a proposição de políticas de gestão do patrimônio arqueológico na Amazônia, a partir de uma visão êmica (Bezerra, 2010).

As entrevistas realizadas com distintas comunidades da vila e a observação sistemática do cotidiano dos moradores têm como objetivo a discussão, entre outros aspectos, das relações entre a memória social e o patrimônio arqueológico da vila, da sua conexão com a negação do passado indígena, do lugar das ruínas no cotidiano dos moradores e da prática de colecionar objetos arqueológicos.

Neste artigo, apresento algumas reflexões sobre a prática do colecionamento e o papel das ruínas na paisagem percebida pelos moradores. Critico a abordagem reducionista que considera $\mathrm{O}$ ato de colecionar artefatos - em comunidades de pequena escala - uma ameaça à preservação e atribui a sua prática ao desconhecimento e à ignorância das populações locais, que são responsabilizadas pela destruição do patrimônio arqueológico. A questão é complexa e meu argumento é o de que o colecionamento em contextos como o de Joanes não pode ser visto como destruição ou ameaça ao patrimônio arqueológico da Amazônia, mas como forma de lidar com um passado que é, muitas vezes, negado pelas narrativas locais, além de apropriado por esse processo de fruição da cultura material. 
Da mesma forma, entendo que a naturalização das ruínas - observada em Joanes e atribuída ao desconhecimento de sua importância histórica e arqueológica - não significa a sua desvalorização, mas a sua ressemantização (Bezerra, 2009a).

\section{IN SMALL THINGS COLLECTED OU OS PEQUENOS COLECIONADORES DE JOANES}

James Deetz (1996), em seu seminal livro "In Small Things Forgotten: an Archaeology of early american life", que inspirou o título desta seção, discute o status da cultura material para a compreensão da vida social. $\bigcirc$ autor, no final do livro, afirma que:

It is terribly important that the 'small things forgotten' be remembered. For in the seemingly little and insignificant things that accumulate to create a lifetime, the essence of our existence is captured. We must remember these bits and pieces, and we must use them in new and imaginative ways so that a different appreciation for what life is today, and was in the past can be achieved (Deetz, 1996, p. 259-260).

Deetz se referia aos objetos já 'acumulados' e transformados em artefatos arqueológicos e às coisas acumuladas por nós, hoje. $\bigcirc$ autor ressalta o papel da cultura material na construção da existência cotidiana e as possibilidades de elaboração de interpretações criativas sobre o presente e o passado.

Cabe, então, perguntar: por que não adotamos perspectivas criativas no estudo dos objetos arqueológicos acumulados por moradores de pequenas vilas como Joanes? Por que não estudar o papel dessa cultura material no cotidiano das comunidades? Por que não entender as relações entre as pessoas e as 'coisas [colecionadas] do passado', sem partir da ideia de destruição? Não seria interessante seguir a proposta de Deetz (1996) e pensar em "new and imaginative ways so that a different appreciation for what life is today"?

As reflexões de Miller (2005, p. 38) contribuem para essa discussão. Segundo ele, é necessário questionar: "(...) how the things that people make, make people".
Parafraseando o autor, pergunto: como as coisas que as pessoas construíram no passado constroem as pessoas hoje? Por que as teorias da cultura material têm sido aplicadas somente para o entendimento das relações entre 'pessoas e coisas' no passado? Por que não se estender tais estudos para as relações estabelecidas no presente com as coisas do passado?

Em minha perspectiva, isso parece sugerir que a patrimonialização das 'coisas' torna o estudo de sua relação com as sociedades contemporâneas um mero exercício a favor da retórica da preservação. Proponho que, para além da preservação (ou repensando a própria ideia de preservação), se estude etnograficamente as relações entre as comunidades residentes no entorno de sítios arqueológicos na Amazônia e as 'coisas', para que se compreenda a dinâmica da materialização (Bell e Geismar, 2009).

A noção de 'coisa' é discutida por Bell e Geismar (2009) em um artigo que sublinha as 'novas e imaginativas' interpretações elaboradas para o entendimento das relações entre pessoas e coisas na Oceania. No texto, os autores indicam que essa ideia se afina ao processo de materialização, que, para eles, ao contrário da ideia de materialidade, consegue "(...) capture the vitality of the lived processes by which the ideas of objectivity and subjectivity, persons and things, minds and bodies are entangled" (Bell e Geismar, 2009, p. 3). Dessa forma, a categoria 'coisa' é mais adequada à noção de materialização, pois evita a usual naturalização da cultura material como categoria que obscurece distinções locais (Bell e Geismar, 2009, p. 6).

Cabe lembrar que, em seu livro "Materiality", Miller (2005) não sugere outras terminologias, mas também faz uma reflexão crítica sobre materialidade, cultura material e 'coisa'. Com relação ao último, trata do problema da suposição do significado acadêmico do termo e discute o fato de que uma teoria da cultura material tem que estar situada em uma teoria mais ampla de cultura. Bell e Geismar (2009, p. 9) afirmam que as coisas não são apenas representações de ideias sobre cultura, mas agentes na sua construção. 
É nesse sentido que desenvolvo a pesquisa sobre as relações entre as pessoas e as coisas em Joanes, tendo como foco as coisas que denominamos por objetos arqueológicos, artefatos e patrimônio. Os moradores da vila se dividem em relação ao interesse por esse conjunto de coisas que formam o patrimônio arqueológico. Para alguns, as ruínas do sítio PA-JO-46 devem ser preservadas e exploradas pelo turismo; para outros, faz-se necessário construir um museu local; e há aqueles que percebem o patrimônio como um entrave para o crescimento da vila. A escola é um exemplo emblemático da relação ambígua com os bens arqueológicos. Seu prédio está assentado sobre parte do sítio, e foi durante a construção de um banheiro, na década de 1980, que parte importante do sítio foi descoberta. Ali, o patrimônio arqueológico ora é reivindicado como elemento no processo educativo e na constituição da cidadania, ora é considerado um entrave à melhoria da infraestrutura do prédio da escola.

A vila é composta por pessoas nascidas em Joanes, autodenominados 'filhos de Joanes', e pelos 'forasteiros', moradores oriundos de diversas partes do país e estrangeiros. Parte significativa do comércio local (armazéns, pousadas, armarinhos, entre outros) é de propriedade do grupo de 'forasteiros', uma distinção que é marcada nas falas dos moradores e que sugere uma disputa na percepção do patrimônio arqueológico. Esse contexto se assemelha, em certa medida, às reflexões propostas por Elias e Scotson (2000) em seu estudo sobre as relações de poder em uma pequena comunidade nas proximidades de Londres, nos anos 1960, e o papel da 'fofoca' nesse processo. Os autores discutem o fato de que as 'famílias antigas' de Winston Parva ${ }^{4}$ se consideravam 'humanamente superiores' aos moradores considerados como 'os de fora', por terem chegado na pequena cidade em período mais recente. Elias e Scotson (2000) argumentam que um dos meios de controle social de um grupo sobre o outro é a fofoca - elogiosa ou depreciativa -, em função da situação apresentada.
No estudo desenvolvido na Inglaterra, os pesquisadores questionam os meios pelos quais essa crença na superioridade se estabelece. É interessante observar que as discussões propostas se aproximam do caso de Joanes. Os moradores mais antigos criaram a categoria dos 'forasteiros' para qualificar aqueles que seriam os 'de fora' de Winston Parva. Na cidadezinha inglesa, o marcador distintivo dessa oposição era a antiguidade, ou seja, o tempo de moradia no local. Em Joanes, além da antiguidade, o que está em jogo é a origem. Isso porque alguns moradores, considerados como 'forasteiros', residem na vila há tanto tempo quanto algumas 'famílias antigas', contudo, não nasceram na vila. A própria categoria criada para os que se opõem aos 'forasteiros' indica o marcador: 'filhos de Joanes'.

A questão da origem assume, então, um papel central nessa oposição. O patrimônio arqueológico é utilizado como alegoria da relação ancestral com a vila e sua história. Curioso notar que alguns dos 'forasteiros' também se apropriam do patrimônio como um instrumento de inclusão na comunidade, por meio de um discurso preservacionista, que é construído para desqualificar o outro grupo, muitas vezes, responsabilizado pela sua destruição.

Entretanto, um dos principais grupos responsáveis pela destruição do patrimônio é o dos turistas. Europeus, em sua maioria, e brasileiros, de diversas partes do país, protagonizam atitudes de descaso e/ou destruição do sítio. Frequentemente se observa grupos de turistas 'escalando' a torre da igreja para tirar fotografias ou estacionando carros sobre o sítio. Os guias de turismo, vindos de outras localidades, dão informações descontextualizadas, sem fundamento, levando, em muitos casos, a interpretações de natureza fantástica, tais como a existência de um vulcão escondido, de onde teriam sido retiradas as pedras para a construção da igreja, e até a presença Maia na ilha.

O imaginário a respeito da vila, de seu passado e das ruínas também é povoado por narrativas fantásticas. Como em toda a região amazônica, os moradores contam

\footnotetext{
4 Nome fictício dado pelos autores para uma pequena cidade no interior da Inglaterra, que serviu como estudo de caso para a sua pesquisa.
} 
histórias de assombrações envolvendo o sítio, falam da existência de tesouros escondidos e guardam dezenas de objetos arqueológicos. Nas palavras de um ex-aluno: "eles constroem outros sítios arqueológicos em casa" (Agnelo Queiroz, comunicação pessoal, 2010). Nas vilas em que há concentração de sítios pré-coloniais, são os machados e as urnas que mais despertam a atenção. Eles são exibidos em caixas cuidadosamente organizadas, mas também são utilizados como pesos de papel e pesos de porta. Os vasos cerâmicos servem como recipientes de armazenamento de água e farinha, e seus fragmentos são aproveitados como suporte para manter a umidade de mudas de plantas ou como brinquedos para as crianças, que "preferem os mais enfeitadinhos" ${ }^{\text {, }}$, aqueles com decoração plástica.

Em Joanes, o repertório material inclui desde cerâmica indígena até louças, vidro, ferro, ossos e materiais construtivos dos séculos XVI ao XIX. $O$ intenso regime de chuvas na Amazônia provoca o afloramento de material arqueológico que não se restringe à área das ruínas (Figura 2), mas se encontra disperso por toda a vila.

Os moradores coletam os materiais na superfície, não havendo registro de escavações realizadas com o intuito de desenterrar objetos. Contudo, é comum encontrar artefatos durante a execução de obras nas casas ou nas etapas de plantio das roças.

Os moradores ${ }^{6}$ antigos relataram, em suas entrevistas, o achado de moedas e miçangas na área das ruínas, durante a infância. Segundo D. Maria, funcionária aposentada da escola e ceramista, eles não guardavam os objetos encontrados. A sua descrição, assim como as de outros moradores, parece indicar que havia um volume tão significativo desses objetos, que eles eram abandonados no local. Para ela, essa expressiva quantidade de material indica que "devia ter muito índio porque tem muita missanga e eles gostavam de andar enfeitados". Ela lamenta porque

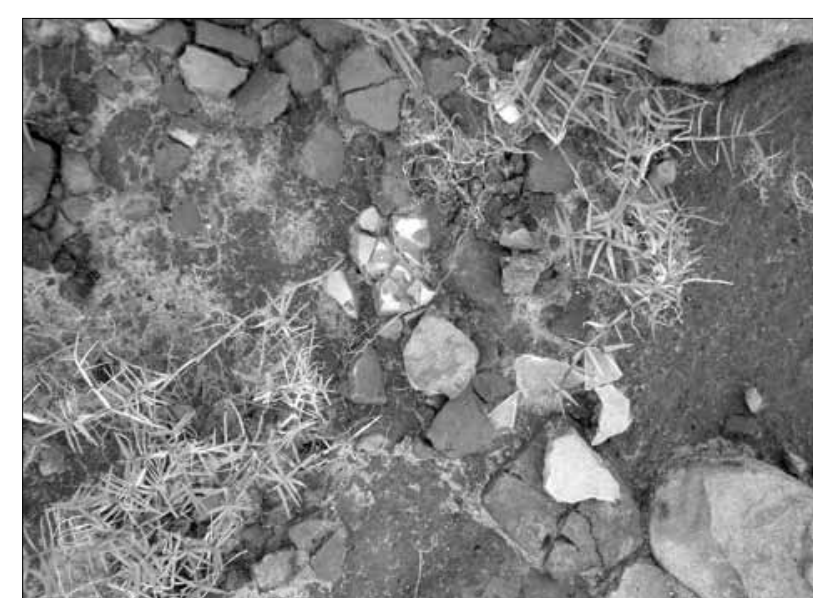

Figura 2. Afloramento de material arqueológico após a chuva. Foto: M. Bezerra.

"agora tá civilizado" e "só resta a lembrança das histórias". D. Maria diz não saber nada dos índios que ali viveram e diz que "tem gente que me acha parecida com índio, eu não sei, mas acredito que seja". Ela se ressente por não ter guardado nenhuma das moedas encontradas na infância.

Alguns moradores guardam pequenas coleções com o cuidado digno de um curador. É o caso da professora Edna, que, após a limpeza dos fragmentos feita por sua neta, 'restaura' os objetos quebrados e faz questão de informar o seu achado e perguntar o que pode ser feito para preservar a peça. Ela e outros moradores doaram várias peças para o projeto. Durante a missão de 2008, seus nomes foram registrados em fichas e expostos ao lado dos objetos doados. A revelação de seus nomes nas fichas improvisadas na mostra de materiais tornou-se mais importante do que os próprios objetos doados. $\mathrm{Na}$ verdade, o pequeno pedaço de papel com a identificação do doador qualificou de tal forma a atitude dos moradores, que impulsionou outras doações e o aumento da visitação de parentes e amigos para conhecer a escavação e, posteriormente, a exposição na escola.

\footnotetext{
5 Fala de uma menina de dez anos, cuja casa está assentada sobre a antiga aldeia na vila de Água Azul, no município de Rurópolis, oeste do Pará, onde se desenvolve o "Programa de Arqueologia Preventiva BR-163 e BR-230", coordenado por Denise Schaan (Universidade Federal do Pará - UFPA).

6 Alguns nomes foram trocados para respeitar o anonimato dos entrevistados.
}

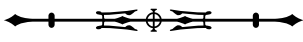


As crianças da vila também coletam objetos arqueológicos nos quintais, nas ruas, no pátio da escola, na praia, e formam 'pequenas coleções', escondidas num primeiro contato pelo medo de perdê-las. As moedas constituem o objeto preferido das crianças. Algumas delas têm coleções que representam uma longa cronologia na história do Brasil (Ravagnani, 2010).

Realizei uma série de entrevistas com um grupo de 11 alunos da Escola de Joanes, com idades entre dez e 12 anos. As duas primeiras etapas ocorreram na sala de exposição organizada na escola e a terceira, na área das ruínas. Na escolha do local da exposição para o encontro com as crianças, considerei as reflexões de Castañeda (2008, p. 40) sobre o que ele denomina de "instalação etnográfica", um lugar onde distintas visões de mundo confluem, possibilitando um diálogo que subverte as relações verticalizadas entre pesquisadores e comunidades locais, e abre espaço para as interpretações sobre a cultura material e a construção do passado. De fato, a observação e as conversas com os moradores na exposição trouxeram à tona aspectos de sua relação com o patrimônio arqueológico até então silenciados.

Durante as entrevistas, as crianças narraram que os índios que moravam na vila jogaram as moedas em um poço, que fica a poucos metros da escola, ao fugirem dos portugueses, que queriam tomar as suas terras. Esse poço faz parte do imaginário dos moradores que acreditam ser o local repleto de tesouros. Ao serem perguntados sobre o material mais antigo que conheciam, os estudantes responderam quase em uníssono: as moedas! As vitrines da pequena exposição mostravam materiais de várias categorias, mas foram as moedas a referência

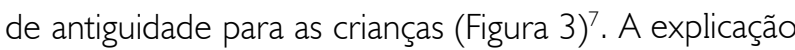
dada por várias delas é que "quando eles nasceram [os índios] as moedas já existiam e aí eles puderam comprar tudo o que estava ali [na vitrine]". Para elas, as moedas pertenciam aos portugueses, mas seus últimos donos

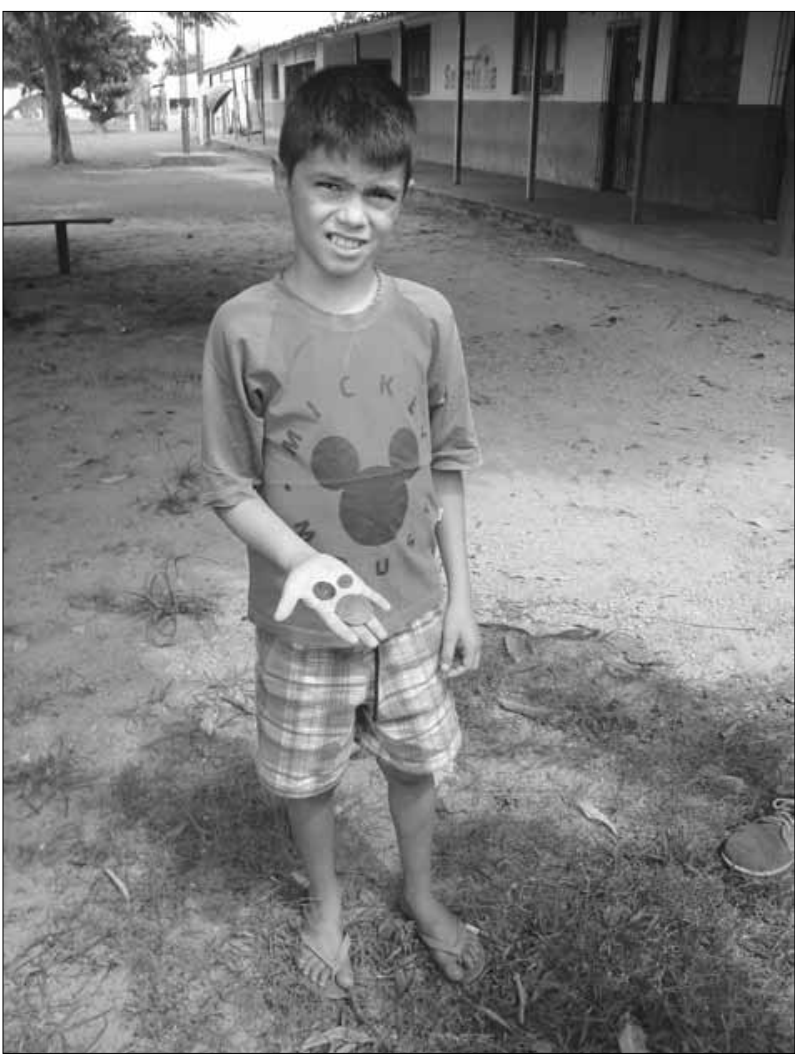

Figura 3. Breno e sua coleção de moedas. Foto: M. Bezerra.

foram os índios, que as jogaram no poço e em outros locais da vila.

De acordo com Deverenski (2000, p. xv), "(..) children perceive, react and add to the world through material culture as objects guide the child's experience". Pesquisas revelam que crianças, durante situações de exceção, como guerras, praticaram o colecionamento como forma de minimizar o sentimento de perda (Belk, 2008). No nosso caso, experienciam o passado da vila e, em certa medida, a perda da terra dos índios para os portugueses.

A propriedade da terra tem papel central na vida das populações amazônicas. Não é surpresa, então, o fato de que crianças que vivem essa realidade elaborem, de forma tão vívida, a imagem dos índios sendo usurpados pelos europeus em seu bem mais precioso - a terra

\footnotetext{
7 Foto utilizada mediante autorização do responsável pelo menor, o pai, professor Emanuel Guedes da Fonseca Junior.
}

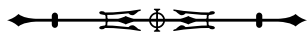


- e revidando a perda ao jogar o metal precioso dos portugueses no fundo de um poço até hoje inacessível.

Apesar de falarem muito sobre os índios, as crianças, assim como a maioria dos moradores de Joanes, afirmam não ter qualquer relação de ancestralidade com as etnias que habitavam a ilha. As crianças repetem o discurso da negação e tratam o patrimônio local como parte da história dos 'outros': índios e portugueses. Por outro lado, o imaginário infantil sobre a relação entre índios e portugueses alimenta o interesse pelas moedas e as torna significativas como parte do universo material indígena. Da mesma forma, ao escolherem objetos para uma exposição fictícia sobre a história de Joanes, apontaram, sem exceção, elementos do repertório material indígena.

Concordo com Belk (2008, p. 534) quando afirma que o colecionamento é um "ritual act of reverence", no qual o colecionador retira objetos de uma situação de desvalorização e "thereby sacralizing them as part of the collection", o que, para ele, caracteriza "an essentially antimaterialistic activity". As coleções formadas por moradores de Joanes - adultos ou crianças - não constituem atos opostos à preservação e à apropriação, mas, ao contrário, são processos singulares de significação e de sacralização dos objetos. Isso cria um paradoxo com relação às ações de preservação, que visam coibir essas práticas por meio de projetos de 'educação' e 'conscientização' sobre a importância do patrimônio, mas que desconsideram os moradores como sujeitos ativos na sua construção.

\section{AS RUÍNAS COMO COISAS OU PAISAGENS PRATICADAS}

As ruínas pouco aparecem nas narrativas das crianças, contudo, durante as entrevistas, elas contaram sobre as brincadeiras realizadas no sítio e descreveram as assombrações que aparecem no seu entorno. As ruínas servem como passagem para a beira do penhasco, para a área do farol e para os fundos da igreja nova, onde gostam de brincar. Os moradores mais antigos também relatam histórias de brincadeiras que aconteciam no mesmo lugar e falam das ruínas como caminho para passeios e caminhadas.

Tanto os velhos como as crianças, ao falarem de lugares que representam Joanes, citam outros domínios. Muitos se referem ao antigo farol, ao poço, outros falam da praia, do igarapé, mas raramente mencionam as ruínas. Curioso notar que muitos dos lugares citados ficam no entorno das ruínas e é preciso atravessá-las para alcançá-los.

As ruínas são naturalizadas pelos moradores, fazem parte de sua paisagem cotidiana. Elas parecem não ter significado, mas estão o tempo todo presentes nas suas lembranças. A sua aparente banalização pode ser entendida como o resultado de um envolvimento tão intenso com esse "conteúdo espacial da existência" (Meneses, 2002, p. 188), que não há espaço para o estranhamento. D. Maria afirma: "desde que eu me entendo, a ruína sempre esteve lá”. Não são eles que habitam as ruínas, são as ruínas que habitam neles. As lembranças de todos com relação às ruínas dizem respeito ao domínio afetivo, a um tempo "passado que se faz presente" (Sarlo, 2007). Nesse sentido, remeto-me a Jeudy (1990), quando diz que as ruínas não são a memória em si, mas a fonte para o seu imaginário. As ruínas de Joanes são paisagens praticadas por várias gerações.

Ignorar esta 'poética do espaço' (Bachelard, 2008) em Joanes é apostar no patrimônio como "tecnologia do governo", como denomina Smith (2007, p. 169), ou seja, um recurso meramente político a serviço da sacralização de lugares e coisas, em detrimento das pessoas.

\section{CONSIDERAÇÕES FINAIS}

É preciso pensar na materialização das relações e não na sua materialidade. $\bigcirc$ processo de materialização é fundamental para se pensar o contexto de Joanes e de outros lugares, onde as coisas mediaram as relações assimétricas durante a colonização (Bell e Geismar, 2009). Bell e Geismar (2009), ao tratarem da relação entre 
museus, coisas e coleções, discutem a materialização como estratégia-chave para a agenda colonialista. É preciso repensar o processo de materialização envolvido na construção dessas coisas do patrimônio na Amazônia, para não se reproduzir, por meio do discurso da preservação, outra estratégia a serviço de um legado colonial, que converte "(...) living persons and human remains into museum [patrimonial] objects (...)" (Bell e Geismar, 2009, p. 9).

Edwards et al. (2006, p. 3) argumentam que o processo colonialista foi "profoundly material" e que foi experienciado por distintas formas de percepção em relação ao universo material. Nesse sentido, afirmo que os estudos de cultura material desenvolvidos em projetos orientados pela Arqueologia Pública e pela Arqueologia Etnográfica são fundamentais para o entendimento dos encontros coloniais na Amazônia.

Por fim, entendo que a relação que as comunidades de Joanes têm com a categoria 'patrimônio arqueológico' não é de destruição, de desconhecimento. Nesse caso, a lógica patrimonial é contrária à percepção que essas populações têm de 'lugares e coisas'. O discurso do patrimônio essencializa a sacralização do passado e seus testemunhos materiais; os moradores, por sua vez, sacralizam o passado ao ressignificar 'lugares e coisas' em suas vidas cotidianas. Esse processo se dá quando os moradores transformam um fragmento de louça histórica 'jogado' no meio da rua em semióforo de sua conexão com o passado. Não há desvalorização nesse processo. Talvez seja pertinente perguntar o que se entende por 'valorização'? Mas essa é uma longa discussão a ser retomada e desenvolvida em outro artigo.

O descompasso entre as duas visões é próprio de relações que "não acontece[m] entre iguais" (Barretto, 2003, p. 25), mas que têm orientado as políticas de proteção ao patrimônio arqueológico no Brasil (Bezerra de Almeida, 2003). Parafraseando Bauman (2003, p. 84), nessa relação, "devorar e não ser devorado" são intenções concorrentes. No campo do patrimônio, o jogo não é diferente: de mecanismo coercitivo na construção de identidades nacionais à matéria de legitimação de identidades étnicas, os aspectos tangíveis das culturas amazônicas têm estado no centro de territórios contestados. Os conflitos têm sua gênese na própria ideia de patrimônio - uma categoria inventada pelo Estado - e que é, por essência, contrária aos processos de autorreconhecimento e de atribuição de identidades. O discurso do 'patrimônio' indica o que é patrimônio e elege os seus 'herdeiros'.

O desenvolvimento de projetos que priorizem o diálogo entre "horizontes semânticos" distintos (Cardoso de Oliveira, 1998, p. 24) contribui para o descentramento das tomadas de decisão sobre a gestão do patrimônio arqueológico e para a legitimação do passado de pequenas comunidades da Amazônia. Um passado ameaçado não pela sua ignorância acerca do patrimônio, mas pelo que ignoramos das relações entre as 'pessoas' e as 'coisas' do passado no presente.

\section{AGRADECIMENTOS}

Ao Conselho Nacional de Desenvolvimento Científico e Tecnológico (CNPq), que financia a pesquisa tratada neste artigo por meio do Edital CHS 2009 e de Bolsa de Produtividade em Pesquisa; aos moradores da vila de Joanes, pela generosa acolhida ao projeto; à Superintendência Regional do IPHAN (PA/AP), pelo apoio aos projetos desenvolvidos em Joanes; ao arqueólogo Fernando Luiz Tavares Marques, do Museu Paraense Emílio Goeldi, pelas profícuas discussões sobre a 'nossa missão' em Joanes; à arqueóloga K. Anne Pyburn, do Departamento de Antropologia da Indiana University, consultora do projeto, pelas reflexões sobre Arqueologia Pública; ao antropólogo Flávio Leonel A. da Silveira, da Universidade Federal do Pará, membro da equipe, pelas críticas e sugestões ao trabalho; aos pareceristas anônimos, pelas construtivas considerações ao texto. Todas as ideias aqui apresentadas são de inteira responsabilidade da autora. 


\section{REFERÊNCIAS}

BACHELARD, G. A Poética do Espaço. São Paulo: Martins Fontes, 2008.

BARRETTO, M. O imprescindível aporte das Ciências Sociais para o planejamento e a compreensão do Turismo. Horizontes Antropológicos, v. 9, n. 20, p. 15-29, 2003.

BAUMAN, Z. Comunidade: a busca por segurança no mundo atual. Rio de Janeiro: Jorge Zahar Editor, 2003.

BELK, R. Collectors and Collecting. In: TILLEY, C.; KEANE, S.; KUCHLER, S.; ROWLANDS, M.; SPYER, P. (Eds.). Handbook of Material Culture. London: Sage, 2008. p. 534-545.

BELL, J. A.; GEISMAR, H. Materializing Oceania: new ethnographies of things in Melanesia and Polynesia. Australian Journal of Anthropology, v. 20, n. 3, p. 3-27, 2009.

BEZERRA, M. 'Nossa Herança Comum': considerações sobre a Educação Patrimonial na Arqueologia Amazônica. In: PEREIRA, E.; GUAPINDAIA, V. (Orgs.). Arqueologia Amazônica. Belém: Museu Paraense Emílio Goeldi/IPHAN/SECULT, 2010. v. 2, p. 1021-1035.

BEZERRA, M. 'Por cima é balangandã, por baixo molambo só': os moradores, as paisagens e as ruínas em um projeto de Arqueologia no Centro Histórico de Salvador/Bahia. In: SILVEIRA, F. L. A.; CANCELA, C. D. (Orgs.). Paisagem e Cultura: dinâmicas do patrimônio e da memória na atualidade. Belém: Editora da Universidade Federal do Pará, 2009a. p. 63-70.

BEZERRA, M. Da 'Arqueologia Circular' e dos 'Arqueólogos Sem Artefatos'. In: FUNARI, P. P. A.; DOMINGUEZ, L.; CARVALHO, A. V.; RODRIGUES, G. B. (Orgs.). Desafios da Arqueologia: depoimentos. Erechim: Habilis, 2009b. p. 206-214.

BEZERRA DE ALMEIDA, M. O Público e o Patrimônio Arqueológico: reflexões para a Arqueologia Pública no Brasil. Habitus, v. 1, n. 2, p. $275-295,2003$.

BROCHADO, J. P. The Social Ecology of the Marajoara Culture. 1980. Dissertação (Mestrado em Antropologia) - University of Illinois, Illinois, 1980.

BRODIE, N. Introduction. In: BRODIE, N.; KERSEL, M. M.; LUKE, C.; TUBB, K. W. (Eds.). Archaeology, Cultural Heritage and the Antiquities Trade. Gainesville: University of Florida Press, 2006, p. 1-24.

CARDOSO DE OLIVEIRA, R. O Trabalho do Antropólogo. Brasília: Paralelo 15; São Paulo: UNESP, 1998.

CASTAÑEDA, Q. E. The 'Ethnographic Turn' in Archaeology. Research Positioning and Reflexivity in Ethnographic Archaeologies. In: CASTAÑEDA, Q. E.; MATTHEWS, C. N. (Eds.). Ethnographic Archaeologies: reflections on stakeholders and archaeological practices. Plymouth: Altamira Press, 2008, p. 25-61.
CASTAÑEDA, Q. E.; MATTHEWS, C. N. (Eds.). Ethnographic Archaeologies: reflections on stakeholders and archaeological practices. Plymouth: Altamira Press, 2008.

COLETÂNEA de Leis sobre preservação do patrimônio. Rio de Janeiro: IPHAN, 2006.

DEETZ, J. In Small Things Forgotten: an archaeology of early american life. New York: Anchor, Doubleday, 1996.

DEVERENSKI, J. S. Preface. In: DEVERENSKI, J. S. (Ed.). Children and Material Culture. London: Routledge, 2000. p. xv-xvii.

EDGEWORTH, M. (Ed.). Ethnographies of Archaeological Practice: cultural encounters, material transformations. Lanham: AltaMira Pres, 2006.

HAMILAKIS, Y.; ANAGNOSTOPOULOS, A. (Eds.). Archaeological Ethnographies. Cambridge: Maney Publishing, 2009. (Public Archaeology, v. 8, n. 2-3).

EDWARDS, E.; GOSDEN, C.; PHILLIPS, R. B. (Eds.) Sensible Objects: colonialism, museums and material culture. New York: Berg, 2006.

ELIAS, N.; SCOTSON, J. L. Os Estabelecidos e os Outsiders: sociologia das relações de poder a partir de uma pequena comunidade. Rio de Janeiro: Jorge Zahar, 2000.

FAUSTO, Boris. História do Brasil. São Paulo: EDUSP, 2003

FUNARI, P. P. A. Public Archaeology in Brazil. In: MERRIMAN, N. (Ed.). Public Archaeology. London: Routlegde, 2004. p. 202-210.

JEUDY, H. P. Memórias do Social. Rio de Janeiro: Forense, 1990.

LANE, P. Present to Past: Ethnoarchaeology. In: TILLEY, C.; KEANE, W.; KUCHLER, S.; ROWLANDS, M.; SPYER, P. (Eds.). Handbook of Material Culture. New York: Sage, 2008. p. 402-424.

LECOMPTE, M. D.; SCHENSUL, J. S. Designing \& Conducting Ethnographic Research. Walnut Creek, CA: Altamira Press, 1999.

LIMA, H. Projeto BaixoAmazonas. In: SEMINÁRIOINTERNACIONAL DE GESTÃO DO PATRIMÔNIO ARQUEOLÓGICO PANAMAZÔNICO, 1., 2007, Manaus. Anais... Manaus: IPHAN, 2007.

LOPES, P. R. C. A colonização portuguesa da Ilha de Marajó: espaço e contexto arqueológico-histórico na Missão Religiosa de Joanes. 1999. 200 f. Dissertação (Mestrado em História) - Pontifícia Universidade Católica do Rio Grande do Sul, Porto Alegre, 1999.

MARQUES, F. L. T.; BEZERRA, M. Projeto de Pesquisa Arqueológica e Educação Patrimonial na Vila de Joanes, Ilha do Marajó. Relatório Parcial. Belém, 2009.

MARQUeS, F. L. T.; BEZERRA, M. Projeto de Pesquisa Arqueológica e Educação Patrimonial na Vila de Joanes, llha do Marajó. Relatório Parcial. Belém, 2008. 
MEGGERS, B. J.; EVANS, C. Uma interpretação das culturas da Ilha de Marajó. Belém: Instituto de Antropologia e Etnologia do Pará, 1954.

MELLO E SOUZA, L. Formas provisórias de existência: a vida cotidiana nos caminhos, nas fronteiras e nas fortificações. In: MELLO E SOUZA, L. (Org.). História da vida privada no Brasil: cotidiano e vida privada na América Portuguesa. São Paulo: Companhia das Letras, 1997. v. 1, p. 41-81.

MENESES, U. T. B. Identidade Cultural e Arqueologia. In: BOSI, A. (Org.). Cultura brasileira: temas e situações. 4. ed. São Paulo: Ática, 2002. p. 182-190.

MESKELL, L. Archaeological Ethnography: conversations around Kruger National Park. Archaeologies, v. 1, n. 1, p. 81-100, 2005.

MILLER, D. (Ed.). Materiality. Durham: Duke University Press, 2005.

MORTENSEN, L.; HOLLOWELL, J. (Eds.). Ethnographies \& Archaeologies: iterations of the past. Gainsville: University Press of Florida, 2009

PACHECO, A. S. À Margem dos “Marajós”: cotidiano, memórias e imagens da "Cidade-Floresta". Belém: Paka-Tatu, 2006.

PYBURN, K. A.; BEZERRA, M. Arqueologia Pública em 5 tempi: reflexões sobre o workshop 'Gerenciamento do PatrimônioCultural-Arqueologia', Goiânia, Brasil. In: LIMA FILHO, M. F; BEZERRA, M. (Orgs.). Os Caminhos do Patrimônio no Brasil. Goiânia: Editora Alternativa, 2006. p.183-190.

PYBURN, K. A.; WILK, R. Responsible Archaeology is applied Anthropology. In: LYNOTT, M. J.; WYLIE, A. (Eds.). Ethics in American Archaeology. Washington: SAA, 2000. p. 78-83.
RAVAGNANI, L. O passado, o sítio e a escola: as relações entre a comunidade escolar e o sítio histórico de Joanes (PA-JO-46). Relatório Parcial. Bolsa de Iniciação Científica. Universidade Federal do Pará/FAPESPA. Belém, 2010.

ROOSEVELT, A. C. Moundbuilders of Amazon: geophysical archaeology on Marajó Island, Brazil. San Diego: Academic Press, 1991.

SARLO, B. Tempo passado: cultura da memória e guinada subjetiva. São Paulo: Companhia das Letras; Belo Horizonte: Editora UFMG, 2007.

SCHAAN, D. P. Sobre índios e portugueses: arqueologia e história da ilha de Marajó. In: SCHAAN, D. P. (Ed.). Marajó: Arqueologia, Iconografia, História e Patrimônio - Textos Selecionados. Erechim: Habilis, 2009. p. 29-42.

SCHAAN, D. P. Múltiplas vozes, memórias e histórias: por uma gestão compartilhada do patrimônio arqueológico na Amazônia. Revista do Patrimônio Histórico e Artístico Nacional, n. 33, p. 109-136, 2007.

SCHAAN, D. P. Into the Labyrints of Marajoara Pottery: status and cultural identity in prehistoric Amazonia. In: MCEWAN, C.; BARRETO, C.; NEVES, E. (Eds.). Unknown Amazonia: culture in nature ancient Brazil. Londres: The British Museum Press, 2001. p. $108-133$

SCHAAN, D.; MARQUES, F. L. T. Projeto Preservação, conservação, pesquisa e educação patrimonial no sítio histórico de Joanes. Relatório Final. Belém: Museu Paraense Emílio Goeldi, 2006.

SHACKEL, P. A.; CHAMBERS, E. J. (Eds.). Places in mind: public archaeology as applied anthropology. Londres: Routledge, 2004.

SMITH, L. Empty gestures? Heritage and the Politics of Recognition. In: SILVERMAN, H.; RUGGLES, D. F. (Eds.). Cultural Heritage and Human Rights. New York: Springer, 2007. p. 159-171. 